\title{
Electrochemical Oxidation of the Paracetamol in its Commercial Formulation on Platinum and Ruthenium Dioxide Electrodes
}

\author{
Mohamed Bertél , Foffié Thiéry Auguste Appia ${ }^{1}$, Ibrahima Sanogo ${ }^{2}$, Lassiné Ouattara, ${ }^{1, *}$ \\ ${ }^{1}$ Laboratoire de Chimie Physique, UFR SSMT, Université Félix Houphouët-Boigny de Cocody, \\ Abidjan, 22 BP 582 Abidjan 22, Côte d'Ivoire \\ ${ }^{2}$ Centre Hospitalier Universitaire (CHU Treichville) de Treichville, Abidjan, 01 BP V3 Abidjan 01, \\ Cote d'Ivoire \\ *E-mail: ouatlassine@yahoo.fr
}

doi: $10.20964 / 2016.09 .44$

Received: 30 May 2016 / Accepted: 5 July 2016 / Published: 7 August 2016

$\mathrm{Pt}$ and $\mathrm{RuO}_{2}$ electrodes have been prepared thermally at $400^{\circ} \mathrm{C}$ on titanium substrates. The physical and electrochemical characterization showed that the surface of the platinum electrode is smooth, compact and almost homogeneous and that of $\mathrm{RuO}_{2}$ is rough with a mud cracked structure. The voltammetric investigations revealed that the oxidation of the paracetamol occurs on both the prepared electrode. That organic oxidation occurs via a process that involves a direct electron transfer at the surface of the electrode and by an indirect oxidation process via $\mathrm{OH}^{\cdot}$ species and possibly via other in situ redox species. On both the electrodes, the paracetamol oxidation process is diffusion controlled. In the presence of $\mathrm{Cl}^{-}, \mathrm{NO}_{3}^{-}$or $\mathrm{PO}_{4}^{3-}$ the oxidation of paracetamol still occurs via a direct electron transfer in the water stability domain and via an indirect oxidation routes in the higher potential domain by oxidative species resulting from the oxidation of $\mathrm{Cl}^{-}, \mathrm{NO}_{3}^{-}$or $\mathrm{PO}_{4}^{3-}$. The addition of such ions in the electrolyte increases the kinetic of the paracetamol oxidation. This increase is low for all the ions on $\mathrm{RuO}_{2}$ electrode but it is high with $\mathrm{Cl}^{-}$or $\mathrm{NO}_{3}^{-}$on $\mathrm{Pt}$ and low with $\mathrm{PO}_{4}^{3-} \cdot \mathrm{pH}$ studies have revealed that the protonation form of the molecule undergoes a rapid oxidation than the deprotonated form on $\mathrm{Pt}$. On $\mathrm{RuO}_{2}$, the $\mathrm{pH}$ influence is very low compared to platinum electrode.

Keywords: platinum, ruthenium dioxide, cyclic voltammetry, paracetamol oxidation.

\section{FULL TEXT}

(C) 2016 The Authors. Published by ESG (www.electrochemsci.org). This article is an open access article distributed under the terms and conditions of the Creative Commons Attribution license (http://creativecommons.org/licenses/by/4.0/). 